\title{
Urethral Cancer by AJCC v8 Stage
}

National Cancer Institute

\section{Source}

National Cancer Institute. Urethral Cancer by A/CC v8 Stage. NCI Thesaurus. Code C140457.

A term that refers to the staging of urethral cancer according to the American Joint Committee on Cancer, 8th edition. This staging system applies to urothelial (transitional cell), squamous, and glandular carcinomas of the urethra and to urothelial (transitional cell) carcinomas of the prostate and prostatic urethra. It does not apply to squamous cell carcinomas of the penile foreskin (are staged according to the classification for penis), primary urothelial carcinomas of the bladder with transmural involvement of the prostate (are staged according to the classification for urinary bladder), prostatic adenocarcinomas (are staged according to the classification for prostate), mucosal melanomas of the urethra (no AJCC staging system), lymphomas (are staged according to the classification for Hodgkin and non-Hodgkin lymphoma), and sarcomas (are staged according to the classification for soft tissue sarcoma of the abdomen and thoracic visceral organs). (from AJCC 8th Ed.) 